Fourth International Conference on Sustainable Construction Materials and Technologies http://www.claisse.info/Proceedings.htm

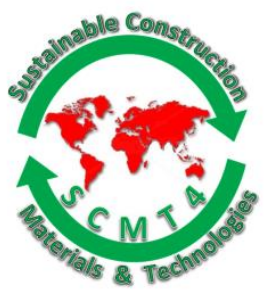

SCMT4

Las Vegas, USA, August 7-11, 2016

\title{
Extraction of Asphalt from Asphalt Concrete Using Subcritical Water
}

\author{
Rétyce I. Amoussou*1, M. Sasaki ${ }^{2}$, and M. Shigeishi ${ }^{3}$ \\ ${ }^{1}$ Graduate School of Science and Technology, Kumamoto University, 2-39-1, Kurokami, Chuo-ku, \\ Kumamoto, 860-8555, JAPAN, Email: 〈dodjy7@yahoo.fr>. \\ ${ }^{2}$ Institute of Pulsed Power Science, Kumamoto University, 2-39-1, Kurokami,Chuo-ku, Kumamoto, 860- \\ 8555, JAPAN, Email: 〈msasaki@kumamoto-u.ac.jp>. \\ ${ }^{3}$ Graduate School of Science and Technology, Kumamoto University, 2-39-1, Kurokami, Chuo-ku, \\ Kumamoto, 860-8555, JAPAN, Email: 〈shigeishi@civil.kumamoto-u.ac.jp〉.
}

\begin{abstract}
Although asphalt concrete is recyclable, recycled asphalt mix is less durable than virgin asphalt mix due to the mixing of deteriorated straight and polymer modifier asphalt, and various chemical additives. Therefore, to improve the quality of recycled asphalt mix, extraction of deteriorated asphalt from asphalt concrete prior to its recycling is essential. It could enable further adequate chemical processing of the extracted asphalt. Thus, the extraction of asphalt from the residues of pulsed power discharge inside asphalt concrete lumps was conducted in an autoclave. The effect of treatment time and cooling conditions on asphalt extraction was investigated at $300^{\circ} \mathrm{C}, 450 \mathrm{rpm}$, and $2 \mathrm{~mL} / \mathrm{g}$ as respective temperature, stirrer speed, and ratio of the amount of water to that of the residues. The authors found that $3 \mathrm{~h}$ as treatment time, refraining from stirring during treatment, and continuous stirring at $450 \mathrm{rpm}$ during natural cooling to a temperature corresponding to the softening point of the recovered pure asphalt represent the optimum asphalt extraction conditions. Finally, penetration, softening point, and ductility tests were performed on the recovered pure asphalt. Results of asphalt properties tests suggest that the extracted asphalt still contained a significant amount of polymer modifier and relatively small amount of oily components. For this reason, the extracted asphalt requires further adequate rejuvenation to improve its quality as construction material.
\end{abstract}

\section{INTRODUCTION}

\section{Background}

Recycling of construction and demolition waste (CDW) including asphalt concrete waste is essential to save financial resources and mitigate environmental issues such as deforestation, natural resources depletion, and air and water resources pollution [Pacheco-Torgal 2013]. Although asphalt concrete is recyclable, recycled asphalt mix is less durable than virgin asphalt mix due to the mixing of deteriorated straight and polymer modifier asphalt and various chemical additives [JMAA 2007; Watson 2011; Kubo 2009]. Asphalt concrete is composed of asphalt and aggregate. Asphalt, also known as bitumen derives from the fractional distillation of crude oils at temperature ranging from 300 to $350^{\circ} \mathrm{C}$ or from natural 
deposits such as bituminous sands [McNally 2011]. Asphalt consists of asphaltenes, resins, aromatics, and paraffins. To satisfy increasing demands for energy in terms of light hydrocarbons, refineries upgrade part of asphaltenes-rich fractions into lighter ones [Wang and Anthony 2003]. In fact, consumption of fossil fuels is estimated to increase and stabilize from 2025 to 2075 [Mohr, Wang, Ellem, Ward, and Guirco 2015]. In addition, as a non-renewable natural resources [Höök and Tang 2013], oil reserves are expected to be exhausted by 2042 [Shafiee and Total 2009]. Generally, asphalt contained in asphalt concrete wastes has lost a substantial amount of its low molecular weight components namely the aromatics and paraffins and thus; consists mainly of asphaltenes and resins [McNally 2011].

Consequently, to promote sustainable management of asphalt concrete wastes and crude oils; and improve the quality of recycled asphalt it is essential to extract asphaltenes-rich asphalt from asphalt concrete waste and investigate its recyclability and upgradability into lighter hydrocarbons. To this end, while sub-and supercritical water has been used to process fuels materials such as bituminous sands [Brunner 2014]. Few pieces of research have investigated the application of subcritical water to the recycling of asphalt concrete. In one study, Kano and colleagues successfully removed asphalt from asphalt mixture using hightemperature and-pressure water [Kano, Akiba, and Kuriyagawa 2006]; in another, asphalt was shown extractable from asphalt concrete using a Soxhlet extraction set-up [Brunner 2014].

\section{Objectives}

The authors have proposed the application of pulsed power discharge [Shigeishi et al. 2013; Akiyama 2003; Amoussou, Ishimatsu, Oyama, and Shigeishi 2015], and subcritical water to extract asphalt from asphalt concrete lumps (Figure 1). This paper focuses on the extraction of asphalt from the residues of pulsed power discharge applied to asphalt concrete lumps in subcritical water. The two goals of this paper are to investigate the performance of subcritical water at extracting asphalt from the residues and to determine the optimum treatment time and cooling conditions.

\section{MATERIALS AND METHODS}

\section{Production of the asphalt concrete residues}

The authors have previously applied pulsed power discharge to separate asphalt concrete into recycled aggregate and residues containing asphalt [Amoussou et al. 2015]. Figure 2 shows production of residues due to pulsed power discharge to the interior of submerged pieces of asphalt concrete lumps. The residues were composed of fine aggregate and asphalt binder.

\section{Subcritical water extraction}

The critical temperature and pressure of water are $373.946^{\circ} \mathrm{C}$ and $22.064 \mathrm{MPa}$, respectively [Brunner 2014]. Water under either temperature below $373.946^{\circ} \mathrm{C}$ or pressure lower than $22.064 \mathrm{MPa}$, is considered to be in subcritical condition. Asphalt was recovered from the above residues using subcritical water in an autoclave (Figure 3) with internal volume of 500ml (OM LABTECH, CO, Ltd., Japan). At the start, about $50 \mathrm{~g}$ of residues with an asphalt content of $7.86 \%$ and $100 \mathrm{ml}$ of water were loaded to the autoclave, which was subsequently heated to $300{ }^{\circ} \mathrm{C}$ (Figure 4). After four different treatment times $(1,2,3$, and $4 \mathrm{~h}$ ) had elapsed, the heater was stopped. The stirrer was inactivated during heating while continuous stirring at 450 rpm was applied during cooling. The stirrer was inactivated again when the internal temperature of the autoclave reached the target temperatures. Cooling conditions of $\mathrm{C} 0$ and $\mathrm{C} 1$ were similar, with the target temperature for $\mathrm{C} 060^{\circ} \mathrm{C}$ and that of $\mathrm{C} 170^{\circ} \mathrm{C}$. 


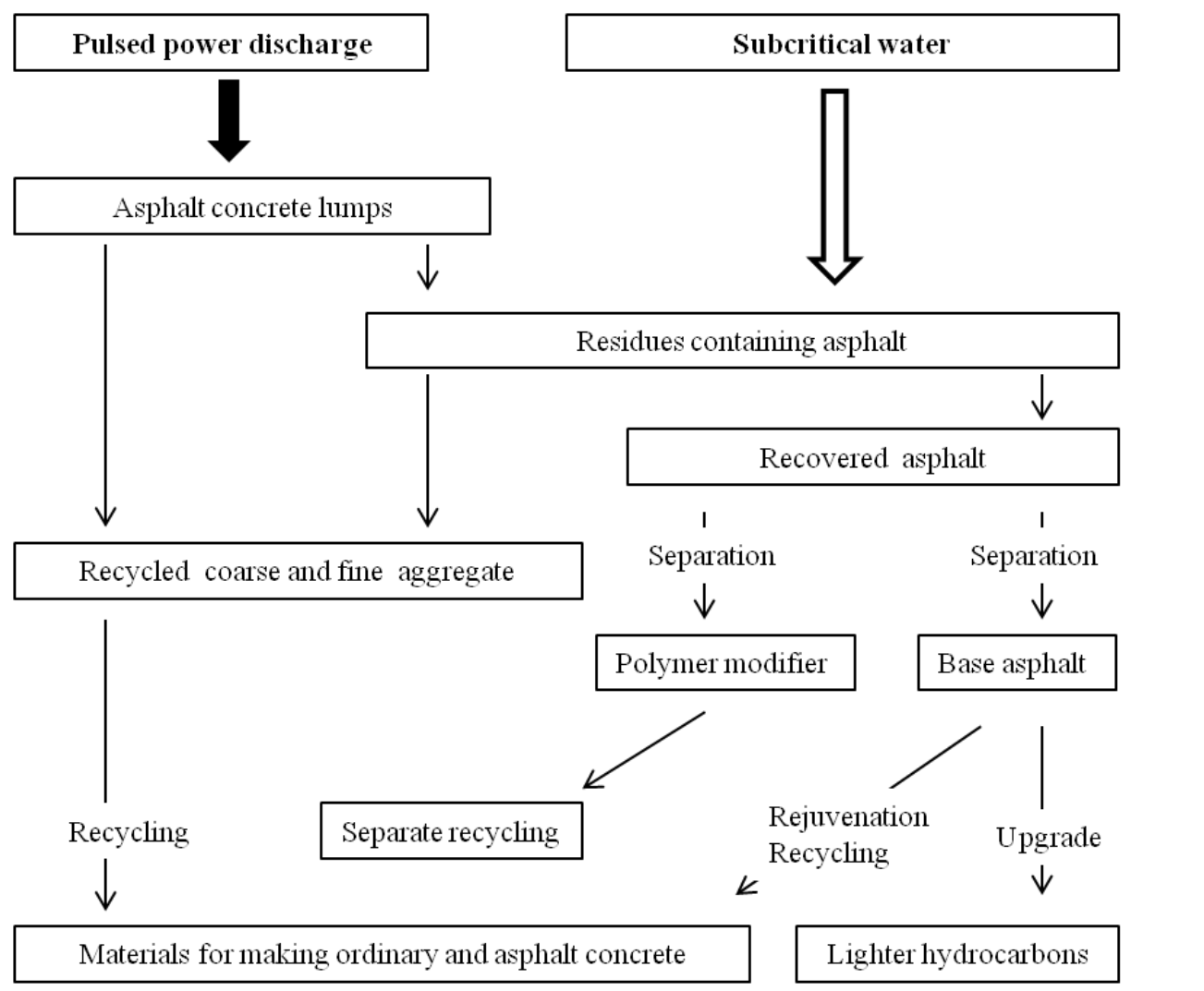

Figure 1. Proposed Asphalt Concrete Recycling

It is the softening point of the recovered pure asphalt produced under cooling condition $\mathrm{C} 0$. The five cooling and heating conditions utilized, C0, C1, C2, C3, and C4, are summarized in Table 1 and Figure 4.

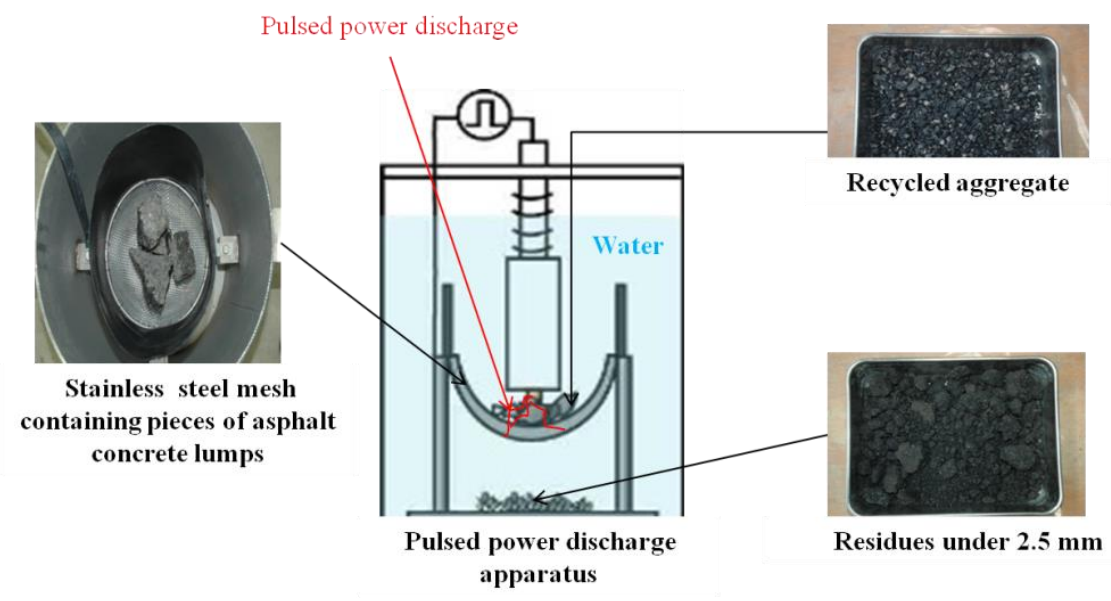

Figure 2. Production of Asphalt Concrete Residues

Cooling conditions $\mathrm{C} 1, \mathrm{C} 2$, and $\mathrm{C} 3$ were conducted to investigate the effects of cooling time on the quality of the recycled aggregate and recovered asphalt, in order to discern the optimum cooling conditions. $\mathrm{C} 0$ and $\mathrm{C} 4$ were applied to confirm the effects of a continuous stirring of the contents of the batch-type reactor of the autoclave on the pure asphalt recovery rate and quality of the recycled aggregate. 


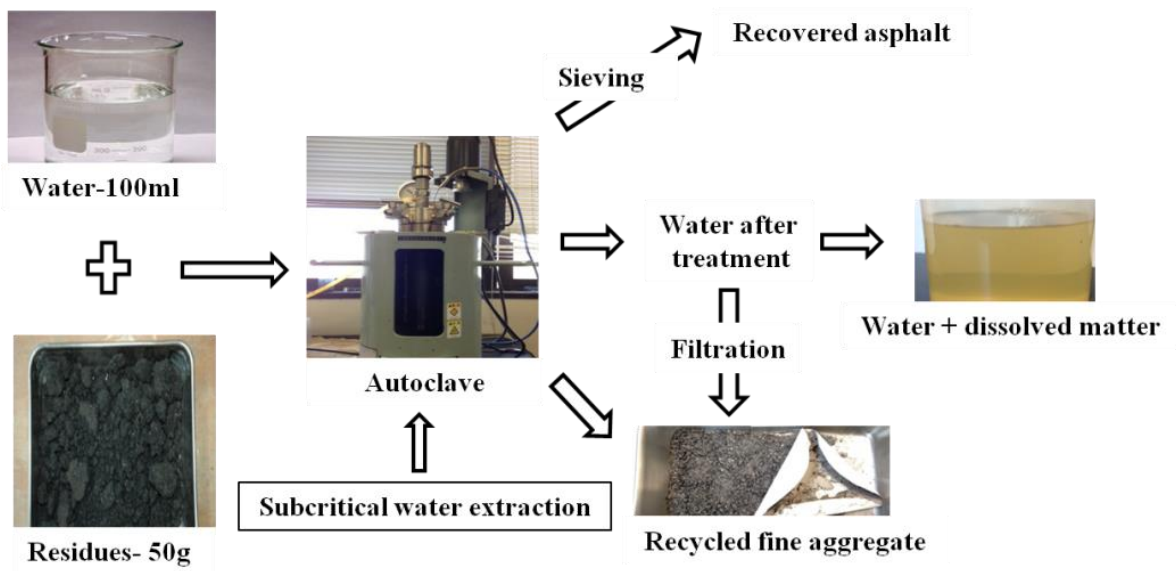

Figure 3. Subcritical Water Extraction

After cooling according to the conditions described in Table 1, products resulting from subcritical water extraction (Figure 3) were categorized as recovered asphalt, recycled aggregate, and water after treatment. The target temperature is the temperature at which the stirrer was turned off.

Table 1. Cooling Conditions

\begin{tabular}{|c|c|c|c|c|c|}
\hline Conditions & C0 & C1 & C2 & C3 & C4 \\
\hline $\begin{array}{c}\text { Target } \\
\text { temperatures } \\
\left({ }^{\circ} \mathrm{C}\right)\end{array}$ & 60 & 70 & 70 & 70 & 55 \\
\hline $\begin{array}{c}\text { Types } \\
\text { of cooling }\end{array}$ & Natural & Natural & Rapid & Rapid & Natural \\
\hline
\end{tabular}

Exclusive of water resulting from the application of cooling conditions $\mathrm{C} 1, \mathrm{C} 2, \mathrm{C} 3$, and $\mathrm{C} 4$, suspended matter was collected by suction filtration as a part of the recycled fine aggregate for $\mathrm{C} 0$. To evaluate amount of recovered asphalt and recycled aggregate, they were dried at room temperature and $105 \pm 5^{\circ} \mathrm{C}$, respectively and weighed. Recovered asphalt was sieved under 1.2, 2.5, 5, 9.5, 16, 19, and $26.5 \mathrm{~mm}$ apertures to determine size distribution.

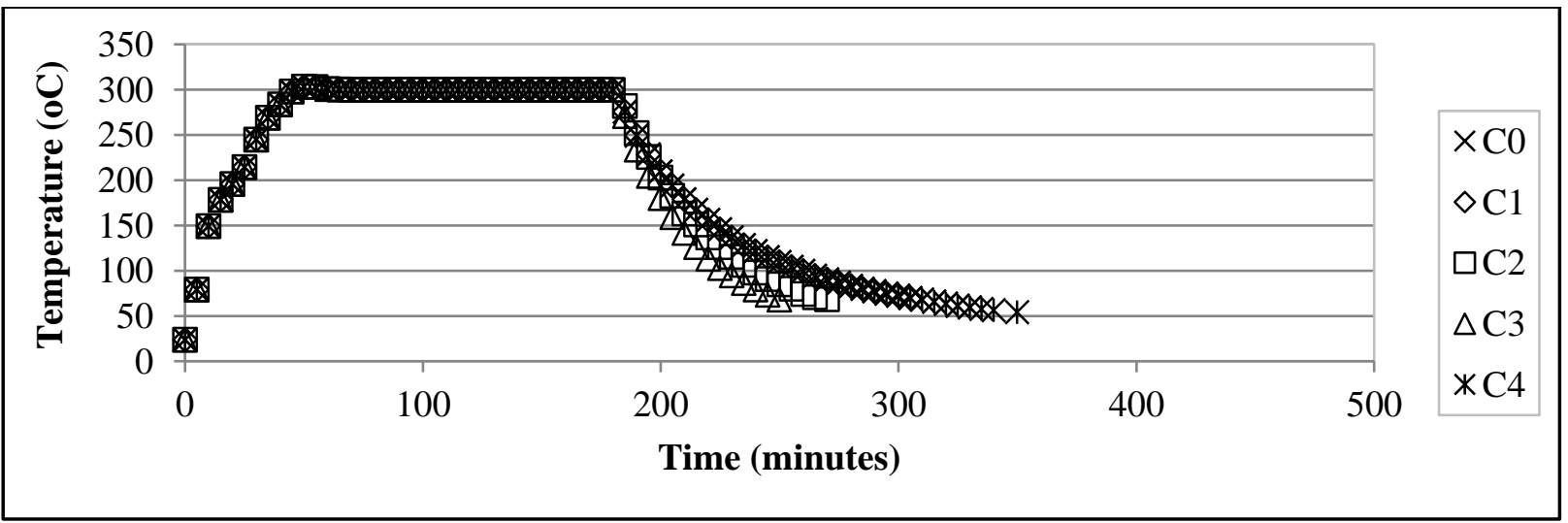

Figure 4. Heating and Cooling Conditions 


\section{Asphalt and aggregate purity and mass balances}

The asphalt ignition method [ASTM D6307-10] was applied to evaluate pure asphalt and aggregate contents of residues, recycled aggregate, and recovered asphalt. Ignition tests were carried out at $540 \pm 5^{\circ} \mathrm{C}$ for $1 \mathrm{~h}$ using an electrical furnace KBF626N1 (Koyo Thermo Systems Co., Ltd., Japan) to investigate pure asphalt and aggregate mass balances according to equations 1 and 2 .

$\mathrm{AS}_{\mathrm{o}}+\mathrm{AS}_{\mathrm{Wo}}=\mathrm{AS}_{\mathrm{RAs}}+\mathrm{AS}_{\mathrm{RAg}}+\mathrm{AS}_{\mathrm{WL}}$

where $\mathrm{AS}_{\mathrm{o}}$ is the pure asphalt content of residues $(\mathrm{g}), \mathrm{AS}_{\mathrm{W}_{\mathrm{o}}}$ is the initial pure asphalt content of water $(\mathrm{g})$, $\mathrm{AS}_{\mathrm{RAs}}$ is the pure asphalt content of recovered asphalt $(\mathrm{g}), \mathrm{AS}_{\mathrm{RAg}}$ is the pure asphalt content of the recycled aggregate $(\mathrm{g})$, and $\mathrm{AS}_{\mathrm{WL}}$ is the asphalt content of water and lost portion of the residues $(\mathrm{g})$.

$\mathrm{AG}_{\mathrm{o}}+\mathrm{AG}_{\mathrm{Wo}}=\mathrm{AG}_{\mathrm{RAs}}+\mathrm{AG}_{\mathrm{RAg}}+\mathrm{AG}_{\mathrm{WL}}$

where $\mathrm{AG}_{\mathrm{o}}$ is the aggregate content of residues $(\mathrm{g}), \mathrm{AG}_{\mathrm{W}_{\mathrm{o}}}$ is the initial aggregate content of water $(\mathrm{g}), \mathrm{AG}_{\mathrm{RAs}}$ is the aggregate content of recovered asphalt $(\mathrm{g}), \mathrm{AG}_{\mathrm{RAg}}$ is the aggregate content of the recycled aggregate $(\mathrm{g})$, and $\mathrm{AG}_{\mathrm{WL}}$ is the aggregate content of water and lost portion of the residues $(\mathrm{g})$.

Recovered asphalt and recycled aggregate purity was computed using equations 3 and 4.

PRAs $=\frac{\mathrm{AS}_{\mathrm{RAs}}}{\mathrm{RAs}} * 100$

where PRAs is the purity of the recovered asphalt $(\%), \mathrm{AS}_{\mathrm{RAs}}$ is the pure asphalt content of recovered asphalt $(\mathrm{g})$, RAs is the mass of recovered asphalt $(\mathrm{g})$.

$\mathrm{PRAg}=\frac{\mathrm{AG}_{\mathrm{RAg}}}{\mathrm{RAg}} * 100$

where PRAg is the purity of the recycled aggregate (\%), $\mathrm{AG}_{\mathrm{RAg}}$ is the pure aggregate content of the recycled aggregate $(\mathrm{g})$; RAg is the mass of recycled aggregate $(\mathrm{g})$.

\section{Properties of recovered asphalt by cooling condition $\mathrm{CO}$}

Penetration, softening point, and ductility tests were performed at the Kumamoto Prefectural Center of Constructional Technology, Kumamoto, Japan on pure asphalt recovered under cooling condition C0.

\section{RESULTS AND DISCUSSION}

\section{Cooling condition C0}

Effect of treatment time. Figure 5 shows that the highest pure asphalt content of recovered asphalt (about $91 \%$ ) and lowest pure asphalt content in recycled aggregate (about $2.1 \%$ ) were achieved at $3 \mathrm{~h}$. These results imply that $3 \mathrm{~h}$ were required to enable an effective separation of asphalt from the recycled aggregate. However, treatment time of $4 \mathrm{~h}$ resulting in mixing of aggregate and asphalt due to continuous stirring during cooling. For this reason, pure asphalt content in the recovered asphalt decreased from $90.75 \%$ to $75.42 \%$ while that in the recycled aggregate increased to $17.8 \%$.

Properties of recovered asphalt by cooling condition $\mathrm{C} 0$ at $3 \mathrm{~h}$. Results of quality tests performed on the recovered pure asphalt produced under cooling condition $\mathrm{C} 0$ are listed in Table 1. 
Table 1. Properties of Recovered Asphalt by Cooling Condition C0 at $3 \mathrm{~h}$

\begin{tabular}{|c|c|c|}
\hline Penetration $(1 / 10 \mathrm{~mm})$ & Softening point $\left({ }^{\circ} \mathrm{C}\right)$ & Ductility $(\mathrm{cm})$ \\
\hline 12 & 70.0 & 1 \\
\hline
\end{tabular}

A comparison of these results with standard properties of asphalt [JMAA 2007] indicates that the extracted asphalt still contains a significant amount of polymer modifier but a relatively small amount of oily components. Consequently, the recovered asphalt hardens, thus requiring proper rejuvenation before being recycled as material for asphalt concrete formation.

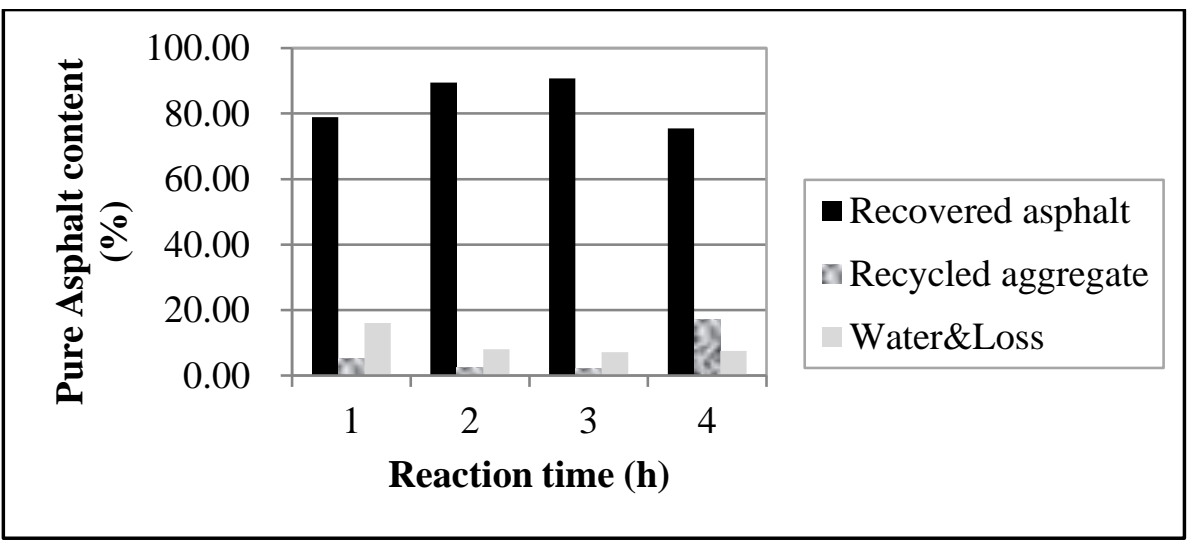

Figure 5. Effects of Treatment Time

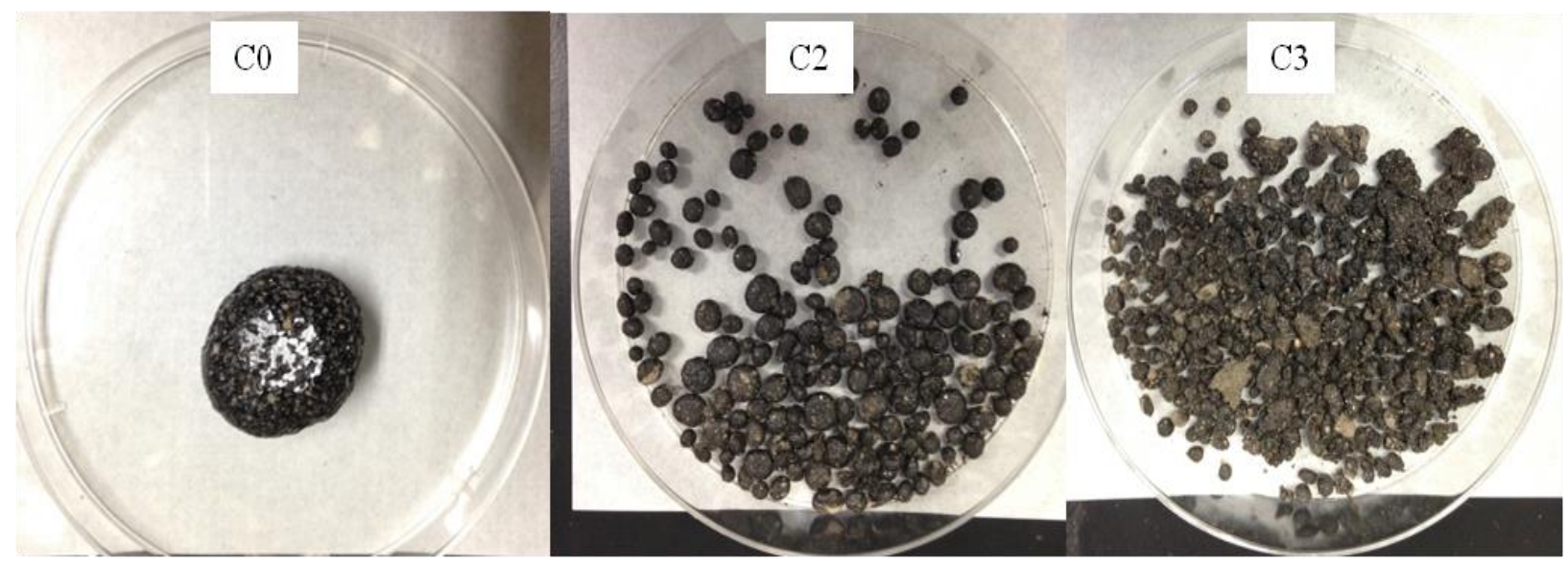

Figure 6. Recovered Asphalt at 3h under Cooling Conditions C0, C2, and C3

Effects of cooling conditions on recovered asphalt and recycled aggregate. Figure 4 shows that approximately 125,90 , and 70 minutes were required for $\mathrm{C} 1, \mathrm{C} 2$, and $\mathrm{C} 3$, respectively, to quench the contents of the autoclave to about $70{ }^{\circ} \mathrm{C}$. Figure 7 illustrates size distribution for recovered asphalt under cooling conditions $\mathrm{C} 0, \mathrm{C} 1, \mathrm{C} 2, \mathrm{C} 3$, and $\mathrm{C} 4$. Conditions $\mathrm{C} 0$ and $\mathrm{C} 4$ produced mainly a spheroid (Figure 6) while $\mathrm{C} 1$ produced a piece of irregularly-shaped recovered asphalt (Figure 8), respectively with sizes smaller than or equal to $26.5 \mathrm{~mm}$ but larger than $19 \mathrm{~mm}$. On the other hand, about $80 \%$ of the granular pieces produced under cooling conditions C2 and C3 (Figure 6) were smaller than or equal to $5 \mathrm{~mm}$ but 
larger than $2.5 \mathrm{~mm}$. When cooling time decreased from 125 to $70 \mathrm{mins}$, the amount of portions larger than $5 \mathrm{~mm}$ but smaller than or equal to $26.5 \mathrm{~mm}$ decreased drastically from $100 \%$ to about $20 \%$.

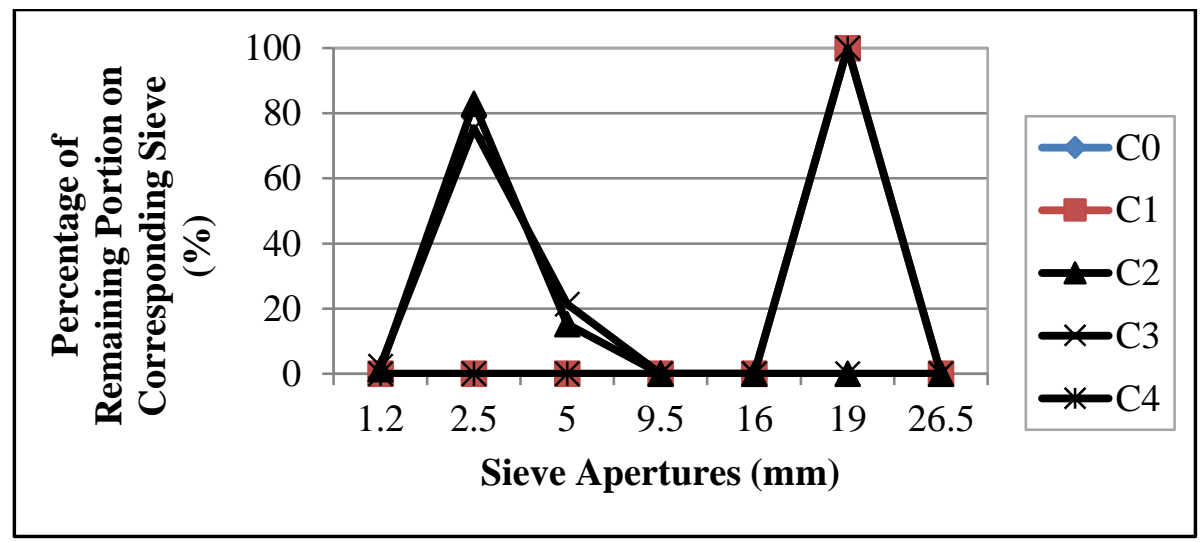

Figure 7. Effects of Cooling Conditions on Recovered Asphalt Size

These results provide compelling evidence that the size of recovered asphalt decreases with decreased cooling time. However, finer sizes of recovered asphalt result in more difficulty in its separation from the recycled aggregate.

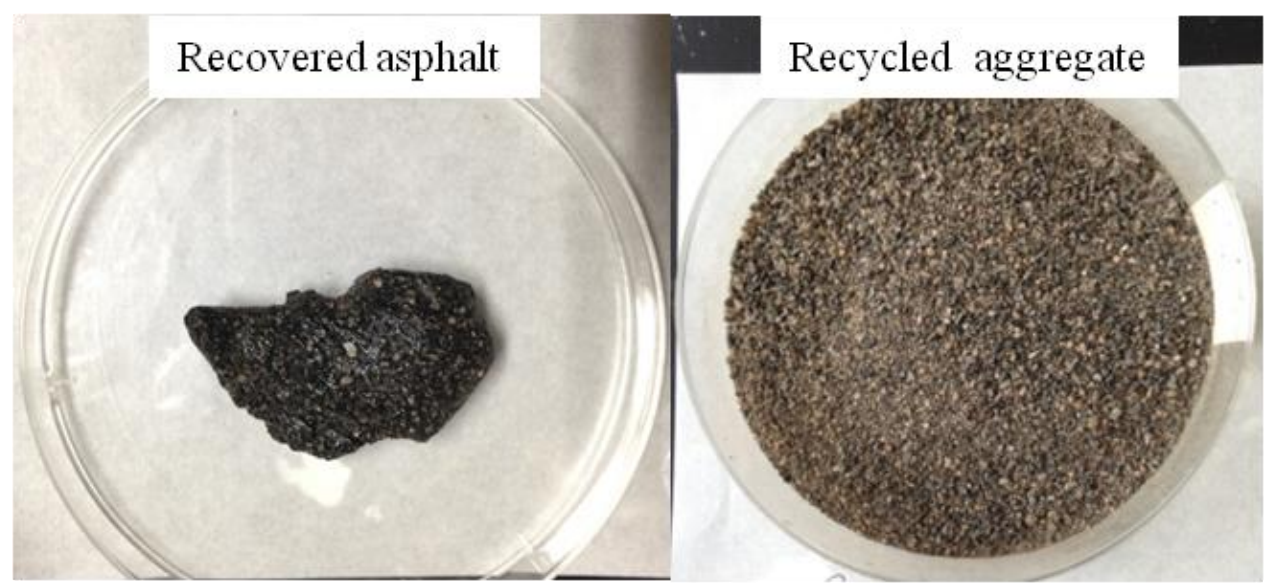

Figure 8. Recovered Asphalt and Recycled Aggregate under Cooling Condition C1

Cooling conditions apparently affected the quality of recycled aggregate and recovered asphalt. Cooling to the softening point of recovered pure asphalt improves the quality of the recycled aggregate by decreasing its asphalt content (Figure 9). Conditions $\mathrm{C} 0$ and $\mathrm{C} 1$ produced almost asphalt-free recycled aggregate compared to $\mathrm{C} 2, \mathrm{C} 3$, and $\mathrm{C} 4$. For instance, when the stirrer was turned off at $55^{\circ} \mathrm{C}(\mathrm{C} 4)$, pure asphalt content of recycled aggregate increased to $2.11 \%$. However, asphalt content of recycled aggregate produced under $\mathrm{C} 1(0.05 \%)$ was lower than that of recycled aggregate produced under $\mathrm{C} 0(0.22 \%)$. On the whole, these results highlight the fact that asphalt content of recycled aggregate increases when cooling time decreases due to the decrease in recovered asphalt size. Furthermore, spheroidization occurred during cooling when the target temperature is inferior to $70^{\circ} \mathrm{C}$ (softening point of the recovered pure asphalt under $\mathrm{C} 0$ ). 


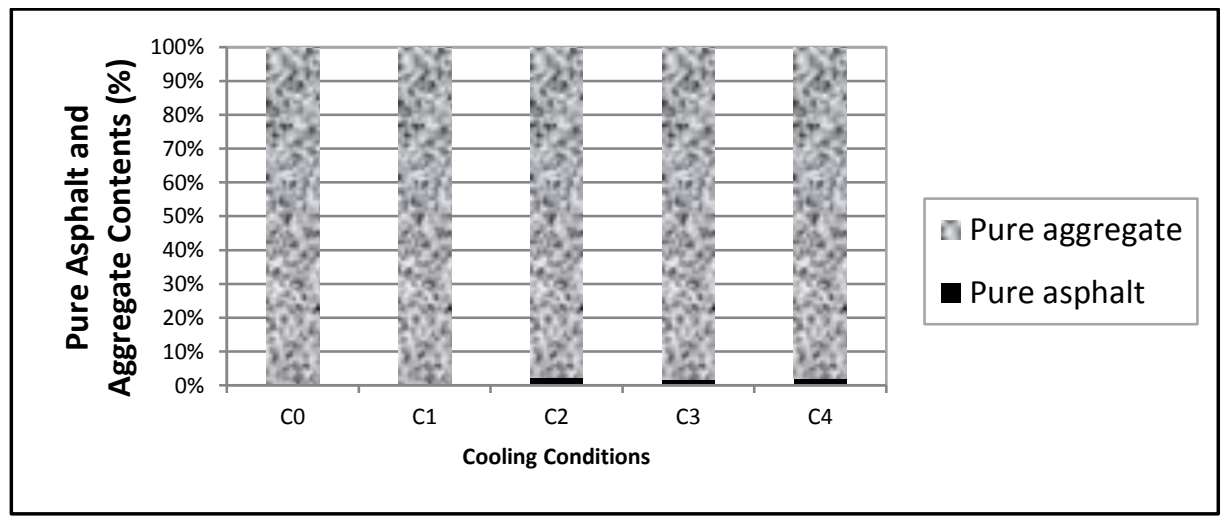

Figure 9. Effects of Cooling Conditions on Aggregate Quality

It is the result of the friction between the solidifying irregularly-shaped recovered asphalt (Figure 8), recycled aggregate (Figure 8), stirrer, and inner part of the batch-type reactor of the autoclave. We could infer that spheroidization required natural cooling to $70^{\circ} \mathrm{C}$ for at least 125 minutes and depended on the shape of the recovered asphalt at the same temperature corresponding to its softening point. The evidence suggests that spheroidization contributed to an increase in asphalt content of recycled aggregate when the contents of the autoclave are quenched to temperatures smaller than that of the softening point of the pure recovered asphalt under natural cooling namely 60 and $55^{\circ} \mathrm{C}$.

Asphalt and aggregate purity and mass balances. Data in Figure 10 show that conditions under $\mathrm{C} 1$ helped to increase the recovery rate of pure asphalt; and to decrease the asphalt contents of recycled aggregate, water, and lost portions of the residues.

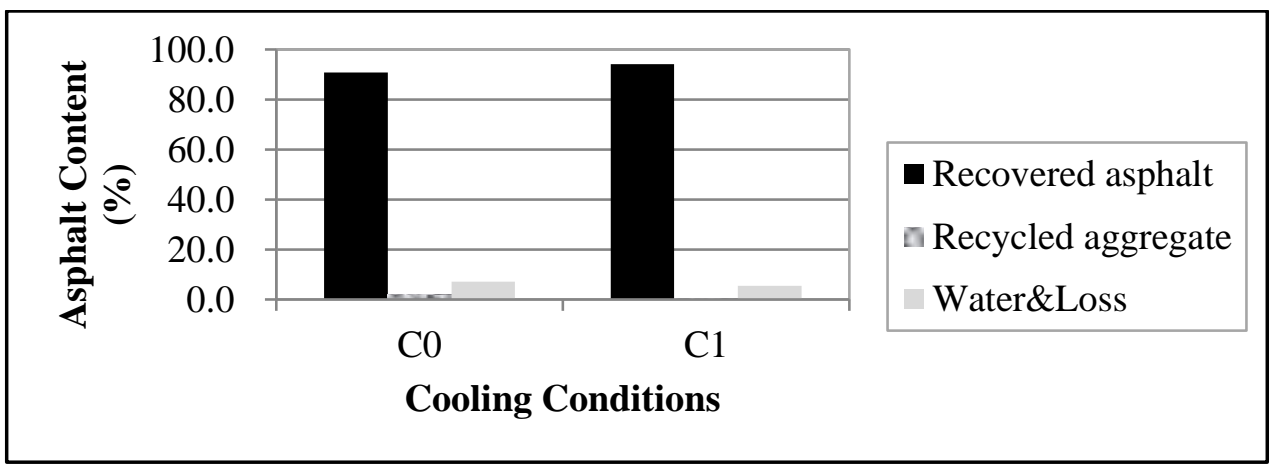

Figure 10. Pure Asphalt Mass Balance for Cooling Conditions C0 and C1

Cooling to about $70^{\circ} \mathrm{C}$ instead of $60^{\circ} \mathrm{C}$ resulted in an increase in the recovery rate of pure asphalt from about $91 \%$ to approximately $94 \%$. While the asphalt content of recycled aggregate decreased significantly from about $2.1 \%$ to $0.4 \%$. Similarly, asphalt content in water and lost portions of the residues decreased slightly from about $7.2 \%$ to $5.6 \%$. These results point to an optimum treatment time and cooling conditions of $3 \mathrm{~h}$ and $\mathrm{C} 1$, respectively. Figure 11 shows asphalt and aggregate purity and mass balances associated with the optimum subcritical water extraction of asphalt from $1000 \mathrm{~g}$ of the residues. 


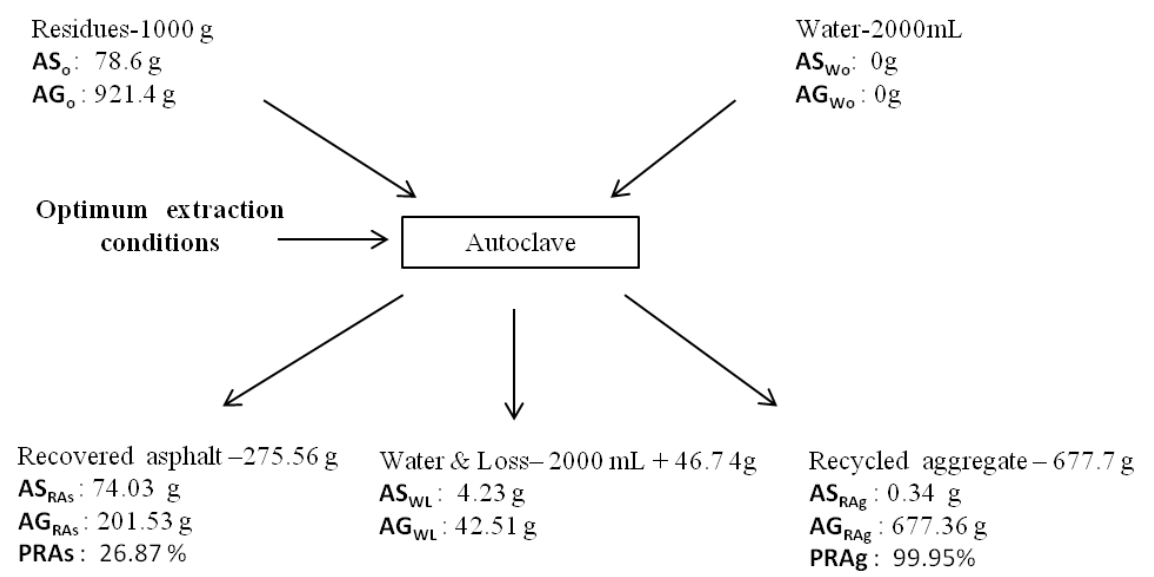

\section{Figure 11. Purity and Mass Balances for Optimum Extraction Conditions}

Though purity of recovered asphalt was only about $27 \%$, it contained about $94 \%$ of the initial pure asphalt content of the residues. Recycled fine aggregate showed extremely high purity (99.95\%), while its pure aggregate content was about $74 \%$ of the initial content of the residues. Pure aggregate content in water and lost portions of the residues was about $42.51 \mathrm{~g}$; this is because under condition $\mathrm{C} 1$, filtration was not carried out to separate residual fine aggregate from water after subcritical water extraction. According to these results, it is probable that residual fine aggregate obtained after filtration of water after subcritical water extraction might have contributed to the increase in the pure asphalt content of the recycled aggregate produced under cooling condition $\mathrm{C} 0$.

\section{CONCLUSION}

In this paper, asphalt was extracted from residues resulting from pulsed power discharge to pieces of asphalt concrete lumps using subcritical water. We found that optimum treatment time at $300^{\circ} \mathrm{C}$ was $3 \mathrm{~h}$ with a stirring speed of $450 \mathrm{rpm}$ and ratio of water amount to residues of $2 \mathrm{~mL} / \mathrm{g}$. The optimum cooling condition was found to be natural cooling to the softening point of the recovered pure asphalt. Recycled aggregate quality improved by decreasing its pure asphalt content and that of water and lost portions of residues. As a result, pure asphalt recovery rate increased as well. At this point, results suggest that natural cooling up to the softening point of the recovered pure asphalt is essential to improve the recovery rate of pure asphalt and quality of recycled aggregate, and facilitate the separation of recovered asphalt from recycled aggregate after its subcritical water extraction from residues. Future work should investigate the effects of the deactivation of the stirrer at temperatures above that of the softening point of the recovered pure asphalt to determine the temperature range at which the stirrer could be inactivated to maximize the pure asphalt recovery rate and purity of the recycled aggregate; and to minimize the amount of lost portions of the residues.

\section{ACKNOWLEDGEMENT}

The authors are grateful to Mr. Daizou Fukuoka, president of Fukuoka Kensetsu-Gouzai located in Yatsushiro-shi, Kumamoto, Japan for providing the asphalt concrete lumps. We would like to thank Dr. Yuichi Tomoda, Kumamoto University, Japan for the laboratory assistance. 


\section{REFERENCES}

Akiyama, H. (2003). “High-Voltage Pulsed Power Engineering.” Ohm-sha. pp.1-2. pp. 36-38. pp. 95.

Amoussou, R., Ishimatsu, K., Oyama, N., and Shigeishi, M. (2015). "Separation of Aggregate from Asphalt Concrete using Pulsed Power Technology." International Journal of GEOMATE, Vol.9, No.1 (Sl. No. 17), 1403-1410.

ASTM D6307-10. "Standard Test Method for Asphalt Content of Hot-Mix Asphalt by Ignition Method." ASTM International, West Conshohocken, PA, 5 pages.

Brunner, G. (2014). "Chapter 7: Processing of Fuel Materials with Hydrothermal and Supercritical Water." Hydrothermal and Supercritical Water Processes, Erdogan Kiran, ed; in the Supercritical Fluids Science and Technology Series, ISBN 978-0-444-59413-6, 666 pages.

Brunner, G. (2014). "Chapter 6: Extractions Processes." Hydrothermal and Supercritical Water Processes, Erdogan Kiran, ed.; in the Supercritical Fluids Science and Technology Series, ISBN 978-0-444-594136, 666 pages.

Brunner, G. (2014). "Chapter 5: Reactions in Hydrothermal and Supercritical Water." Hydrothermal and Supercritical Water Processes, Erdogan Kiran, ed.; in the Supercritical Fluids Science and Technology Series, ISBN 978-0-444-59413-6, 666 pages.

Höök, M., and Tang, X. (2013). "Depletion of Fossil Fuels and Anthropogenic Climate Change- A Review." Energy Policy, 52, 797-809.

Japan Modified Asphalt Association (JMAA). (2007). "Japan Modified Asphalt Association Standards, Quality and Test Methods of Polymer Modified Asphalt for Road Pavement."

Kano, Y., Akiba, S., and Kuriyagawa, Y. (2006). "Separation and Recovery of Aggregate from Asphalt Pavement Wastes using High-Temperature and High-Pressure Water." Journal of the Japan Petroleum Institute, 49 (5), 231-239.

Kubo, K. (2009). "Recycling in Japan.” Pavement Team, Public Works Research Institute, Japan.

McNally, T. (2011). "Chapter 1: Introduction to polymer modified bitumen (PmB)." Polymer Modified Bitumen, Properties and Characterization, McNally Tony, ed.; in the Woodhead Publishing in Materials Series, ISBN 978-0-85709-048-5, 404 pages.

Mohr, S. H., Wang J., Ellem, G., Ward, J., and Guirco D. (2015). "Projection of the World Fossil Fuels by Country." Fuel, 141, 120-135.

Pacheco-Torgal, F. (2013). "Chapter 1: Introduction to the Recycling of Construction and Demolition Waste (CDW)." Handbook of Recycled Concrete and Demolition Waste, Pacheco-Torgal, F., Tam, V. W. Y., Labrincha, J. A., Ding, Y., and de Brito, J., ed.; in Woodhead Publishing Series in Civil and Structural Engineering, ISBN 978-0-85709-682-1, 646 pages.

Shafiee, S., Topal, E. (2009). “When will Fossil Fuel Reserves be Diminished?” Energy Policy, 37, 181189.

Shigeishi, M., Namihira, T., Iizasa, S., Ishimatsu, K., Arifi, E., and Amoussou, R. I. H. D. T. (2013). "Pulsed Power Application to Production of Recycled Aggregate." Proceedings of The 3rd Sustainable Construction Materials and Technologies. Japan Concrete Institute.

Wang, J., and Anthony, E. J. (2003). "A Study of Thermal Cracking Behavior of Asphaltenes.” Chemical Engineering Science, 58, 157-162. 
Watson, E.D. (2011). "Literature review of hot in-place recycling." Florida Department of Transportation. 